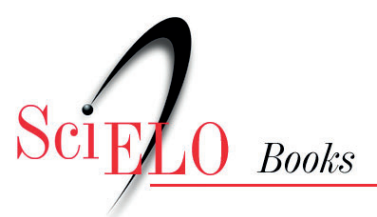

\title{
1. Diagnóstico da educação de jovens e adultos na região Costa Verde do estado do Rio de Janeiro mapeamento do território em subsídio a uma nova agenda política
}

\author{
Elionaldo Fernandes Julião
}

\section{SciELO Books / SciELO Livros / SciELO Libros}

JULIÃO, E.F. Diagnóstico da educação de jovens e adultos na região Costa Verde do estado do Rio de Janeiro: mapeamento do território em subsídio a uma nova agenda política. In: PAIVA, J., comp. Aprendizados ao longo da vida: sujeitos, políticas e processos educativos [online]. Rio de Janeiro: EDUERJ, 2019, pp. 19-39. Pesquisa em educação/Educação ao longo da vida series. ISBN: 978-65990364-9-1. https://doi.org/10.7476/9786599036491.0002.

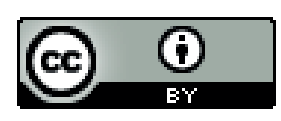

All the contents of this work, except where otherwise noted, is licensed under a Creative Commons Attribution 4.0 International license.

Todo o conteúdo deste trabalho, exceto quando houver ressalva, é publicado sob a licença Creative Commons Atribição $\underline{4.0}$.

Todo el contenido de esta obra, excepto donde se indique lo contrario, está bajo licencia de la licencia Creative Commons $\underline{\text { Reconocimento } 4.0 .}$. 


\section{1}

\section{Diagnóstico da educação de jovens e adultos na região Costa Verde do estado do Rio de Janeiro: mapea- mento do território em subsídio a uma nova agenda política}

Elionaldo Fernandes Julião

\section{Introduçáo}

A história contemporânea da educação de jovens e adultos (EJA) na política nacional de educação tem como importantes marcos legais e principal ponto de partida, a aprovação da Lei de Diretrizes e Bases da Educação Nacional (Lei n. 9.394/96 - LDB) e as suas Diretrizes Nacionais Curriculares (Resolução CNE/CEB n. 01/2000) e Operacionais (Resolução CNE/CEB n. 03/2010), aprovadas, respectivamente em 2000 e em 2010, pela Câmara de Educação Básica do Conselho Nacional de Educação.

Como marcos políticos, evidencia-se o espaço ocupado pela EJA na agenda dos governos, destacando-se a criação, em 2004, da então Secretaria de Educação Continuada, Alfabetização e Diversidade do Ministério da Educação (SECAD); a aprovação do Fundo de Manutenção e Desenvolvimento da Educação Básica 
e de Valorização dos Profissionais da Educação (FUNDEB), que substituiu o Fundo de Manutenção e Desenvolvimento do Ensino Fundamental e de Valorização do Magistério (FUNDEF) a partir de 2007, incluindo as matrículas da EJA na previsão dos seus recursos; os Planos Nacionais de Educação de 2001 (Lei n. 10.172/2001) e de 2014 (Lei n. 13.005/2014), com metas dedicadas à EJA; e a instituição, em 2007, da proposta de Agenda Territorial de Desenvolvimento Integrado de Alfabetização e de Educação de Jovens e Adultos.

A proposta de constituição de uma Agenda Territorial, segundo Resolução n. 65 de 13 de dezembro de 2007, objetivava formular uma ação conjunta do poder público e da sociedade civil em favor da garantia do direito à educação da populaçáo jovem e adulta; tornar-se um instrumento para consolidar estratégias de articulação territorial das ações de alfabetização e de educação de jovens e adultos, estruturadas nas dimensóes técnica, de planejamento e de controle social; integrar açóes do Programa Brasil Alfabetizado e da EJA na definição de uma política pública, a partir do diálogo com os mais diversos parceiros; estabelecer-se, com a indução do MEC, como mecanismo de apoio à estruturação e à institucionalização nos estados, no Distrito Federal e nos municípios, do desenvolvimento integrado de alfabetização e de EJA nos territórios, garantindo a continuidade das aprendizagens dos jovens e adultos, que não se reduzem a processos iniciais de alfabetização.

Como encaminhamento dessa proposta política, em junho de 2008, a então SECAD e o Conselho de Secretários de Educação (CONSED) celebraram pacto de compromisso para o desenvolvimento de ações visando à implementação das Agendas estaduais.

Como membros ativos da Comissão Estadual da Agenda Territorial, as universidades foram convocadas a contribuir na pesquisa como parceiras, oferecendo possibilidades constantes de diagnosticar, mapear, intervir e colaborar na formação dos sujeitos envolvidos. 
O diagnóstico como ação investigativa na proposta da Agenda deveria concomitantemente formar gestores pesquisadores em cada território investigado, com vista - ao mesmo tempo em que se conheciam a realidade e os saberes sobre os quais se assentam as práticas políticas e pedagógicas - a se formarem como sujeitos responsáveis pela atuação política na EJA, na crítica às concepçóes circulantes.

Nessa perspectiva, diante da dificuldade de alcançar os 92 municípios do estado do Rio de Janeiro, em subsídio a políticas públicas integradas, que fortalecessem as necessidades de atendimento à população envolvida — sujeitos de direito —, a presente proposta de pesquisa teve como objetivo elaborar um diagnóstico educacional e educativo das açóes públicas voltadas a jovens, adultos e idosos existentes no subterritório Litoral Sul do estado do Rio de Janeiro (regiáo Costa Verde), que compreende as cidades de Angra dos Reis, Itaguaí, Mangaratiba, Parati e Rio Claro.

Em linhas gerais, em virtude das diversas limitaçóes, a pesquisa procurou: (1) mapear as iniciativas educacionais das redes públicas estaduais e municipais voltadas à EJA, identificando alternativas, modos de fazer, concepçóes, práticas, formas de atendimento, horários, materiais, nomeaçóes etc.; (2) dar subsídios à construção de redes de atores políticos, aproximando instituiçôes e pesquisadores, com vista a otimizar metodologias e procedimentos, no enfrentamento de questóes candentes à realidade regional; e (3) ativar processos de formação de graduandos de todas as áreas, pelo exercício de articulação da pesquisa com parceiros locais, no desenvolvimento da investigação.

Levando em conta as prioridades definidas no plano de açáo da Comissão Estadual para a Agenda Territorial do Rio de Janeiro, a metodologia da pesquisa, para atender os objetivos fixados, pautou-se, em primeiro momento, na coleta quantitativa de dados associadamente a modos de abordagem qualitativa que complementassem as informaçôes recolhidas a princípio. 
Posteriormente, foram utilizadas as bases de dados do IBGE e do INEP, principalmente com relação à obtenção dos dados referentes aos censos demográfico e de educação de 2010 a 2015.

Embora a política de educação para jovens e adultos não seja um tema absolutamente novo no país, ainda náo podemos prescindir, no debate, implícita ou explicitamente, do recurso aos aspectos sociais, políticos e ideológicos que envolvem políticas para as classes populares, principalmente que nos façam refletir sobre suas contradiçóes.

Neste sentido, ampliando as nossas reflexóes sobre o tema na sociedade contemporânea, visando a, efetivamente, avançar na discussão, fundamentado em concepção crítica sobre o papel da política de educaçáo implementada para jovens e adultos das classes populares, temos como objetivo, neste artigo, analisar as perspectivas teóricas, políticas e pedagógicas, principalmente dialogando sobre conceitos de garantias de direitos, políticas públicas, diversidade dos sujeitos, território e desenvolvimento.

Para contribuir com as reflexóes e com o debate, como aportes teóricos da pesquisa, dialogamos com pensamentos e estudos de autores de diversas áreas e correntes das ciências humanas e sociais, destacando-se Amartya Sen (2010) sobre desenvolvimento; Renato Ortiz (2015) sobre universalismo e diversidade; Stephen Ball e Jefferson Mainardes (2011) sobre políticas educacionais; e Richard Sennett (1999) sobre a corrosão do caráter na sociedade contemporânea.

Levando em consideraçáo a proposta da Agenda Territorial, consideramos o conceito de território como importante variável de análise. Mais que buscar as características geoecológicas e os recursos naturais de uma certa área, o que se produz ou quem produz em um dado espaço, ou ainda quais as ligaçóes afetivas e de identidade entre um grupo social e seu espaço, importa entender que o território é, além das dimensôes geográficas, política, 
cultural e econômica, um "[...] espaço definido e delimitado por e a partir de relaçóes de poder” (Souza, 1995, pp. 78-9).

\section{Indicadores sociais de educaçáo no atual contexto nacional e fluminense}

No Brasil, segundo dados divulgados pelo IBGE em 2012, ainda há $8,6 \%$ da população de quinze anos ou mais analfabetas; $8,1 \%$ de jovens entre dezoito e 24 anos frequentando o ensino fundamental; $34,2 \%$ o ensino médio; e $51,3 \%$ o ensino superior.

Embora tenham melhorado, os índices ainda nos mantêm na incômoda marca de ser um dos países com a maior taxa de analfabetismo no mundo, estando à frente de países com menores índices de desenvolvimento humano que o nosso.

Segundo dados do IBGE (2012), o agregado nacional reduziu em $31 \%$ a proporção de pessoas que náo sabiam ler nem escrever, passando de 12,1\% em 2001 para 8,6\% em 2011.

A maior queda no índice de analfabetismo se deu entre os jovens de quinze a 24 anos de idade, cuja taxa passou de 4,2\% para 1,5\% no período considerado. A reduçáo desse índice também foi alta entre as pessoas de 25 a 59 anos de idade (de 11,5\% para 7,0\%).

Esses resultados apontam para o progressivo envelhecimento do perfil do grupo mais afetado pelo analfabetismo. Contudo, isso não significa que a maioria dos analfabetos possui essa faixa etária. Do total de analfabetos acima de quinze anos, 50,7\% têm de 25 a 59 anos de idade, representando um montante superior a 6,5 milhóes de pessoas.

Quanto à média nacional de tempo de estudo entre pessoas com quinze anos ou mais, saltou de sete, em 2001, para 9,6 anos em 2011.

Em 2011, a taxa de frequência bruta a estabelecimento de ensino da população residente, segundo grupos etários, alcançou, 
na faixa de seis a quatorze anos, a marca de $98,2 \%$. Por outro lado, ainda é de $83,7 \%$. na faixa entre quinze a dezessete anos.

$\mathrm{O}$ dado infelizmente nos mostra que, embora estejamos quase universalizando o acesso ao ensino fundamental de crianças na faixa etária de seis a quatorze anos, ainda amargamos o resultado de um grande número de jovens que, por problemas de retenção e evasão, não se mantém estudando.

O Censo Escolar 2015 indica que 2.792.758 estudantes estavam matriculados na educaçáo de jovens e adultos nas redes públicas estaduais e municipais de ensino no Brasil. Desse total, 66,93\% (1.869.426) estavam no ensino fundamental (EF) e 33,07\% (923.332) no ensino médio (EM).

Desde 2008, o país vive um decréscimo no número de matrículas na EJA. Só em 2015, a redução foi 9,48\% (sendo 8,18\% do EF e 2,72\% do EM) em comparação com os dados de 2014, quando foram registradas 3.085.304. Em 2014, a redução foi de 4,97\% em comparação a 2013, que tinha 3.141.566 matrículas e já computava uma redução de 2,95\% (sendo 4,2\% no EF e 0,04\% no EM) em comparação com os dados de 2012, quando foram registradas 3.237.333 matrículas.

Um dado fundamental que deve ser levado em conta ao discutir esses números é que a considerável diminuição no quantitativo de matrículas da EJA vem acompanhada da mudança do perfil dos sujeitos demandantes. Ao contrário do que em geral acontecia décadas antes, quando o público da EJA era majoritariamente de jovens e adultos que não tinham acesso aos bancos escolares, hoje cresce o número de jovens e adultos que tiveram acesso à escola, porém, por motivos diversos, náo conseguiram permanecer nela e concluir os estudos.

Acreditava-se que a universalização do ensino fundamental para crianças a partir dos seis anos de idade diminuiria consideravelmente o público da EJA, principalmente restringindo a 
modalidade da educação básica para os mais velhos que não tiveram oportunidade de estudar antes. Infelizmente, como evidenciado acima, não é o que efetivamente vem acontecendo. Ao contrário, cresce o número de jovens que estiveram na escola, mas que, por diversas questóes, acabaram migrando a partir dos quinze anos para a EJA.

Como podemos evidenciar, a demanda atual por escolarização na EJA ainda é muito grande. Ao contrário do que se pode imaginar, a redução do número de matrículas não está relacionada à diminuição do número dos que necessitam desta política.

A Pesquisa Nacional por Amostra de Domicílios (PNAD), realizada pelo IBGE em 2009, aponta diversos fatores que podem justificar essa situação, destacando-se: a falta de infraestrutura dos espaços escolares para atender demandas dos alunos jovens e adultos; de formação inicial de professores que atuam nessa modalidade; de oferta da EJA em horários alternativos (diurno) para atender os alunos trabalhadores e as mães que não têm com quem deixar os filhos no período de oferta majoritariamente noturno; de articulação entre a EJA e o mundo do trabalho; do não reconhecimento da diversidade dos sujeitos da EJA etc.

Nos últimos anos, o número de jovens com distorção idade-série na educação básica tem alarmado os sistemas de ensino no país, cuja principal causa reside no alto índice de reprovação e abandono escolar, motivados tanto por fatores internos (que envolvem a dimensão ensino-aprendizagem e a gestão pedagógica) quanto por fatores externos (relacionados às questóes econômicas, políticas e sociais) que influenciam todo o sistema educacional. Em 2009, segundos dados do INEP, 20\% dos alunos matriculados na educação básica tinham distorção idade-série. Em 2014, caiu para 14\%; desses, $27 \%$ estão nas séries finais do ensino fundamental e $28 \%$ no ensino médio. 
Levando em conta que a distorção idade-série compromete o Índice de Desenvolvimento da Educação Básica (IDEB) dos estados, a educação de jovens e adultos tem sido reconhecida pelos governos como uma mera estratégia de correção de fluxo, transferindo quase automaticamente os jovens que completam quinze anos para a modalidade EJA ou criando projetos específicos de aceleração de aprendizagem.

O estado do Rio de Janeiro, por exemplo, em 2007, apresentava uma taxa de distorção idade-série de 39\% para o ensino fundamental e 53,1\% para o ensino médio. A Secretaria de Estado de Educação (SEEDUC) criou, em 2009, o Projeto Autonomia, em parceria com a Fundação Roberto Marinho, com o objetivo de promover a aceleração de aprendizagem e a correção da distorção idade-série de alunos do segundo segmento do ensino fundamental (6 $6^{\circ}$ ao $9^{\circ}$ anos) e ensino médio da rede pública, por meio da organização curricular em módulos, unidocência ${ }^{1}$ e de telessalas, podendo concluir o ensino fundamental em apenas doze meses.

Os resultados foram evidenciados nos anos subsequentes, quando o estado do Rio de Janeiro saiu da 26a posição no ranking do IDEB do ensino médio, entre os estados brasileiros, em 2009, para o quarto lugar em 2013. Infelizmente, o aligeiramento não significou maior aprendizado. Pelo contrário, o artifício continua negando o direito à aprendizagem. $\mathrm{O}$ seu real impacto na correção do fluxo escolar só será realmente percebido ao longo da história.

O Censo Escolar 2015 indica que 159.727 estudantes estavam matriculados na educação de jovens e adultos nas redes públicas estadual e municipal de ensino no Rio de Janeiro. Desse total, 62,85\% (100.400) estavam no ensino fundamental e 37,14\% (59.327) no ensino médio.

1. Existência de um único professor para lecionar todas as disciplinas da matriz curricular, com exceção de Educação Física, visto que o Conselho Regional de Educação Física (CREF) conseguiu, em juízo, impedir que as aulas desta disciplina fossem ministradas por profissionais sem formação acadêmica em Educação Física e sem registro no referido órgão. 
O estado do Rio de Janeiro, assim como todo o Brasil, vem vivenciando um decréscimo no número de matrículas na EJA. Só em 2015 a redução foi 2,94\% em comparação aos dados de 2014, quando foram registradas $164.581^{2}$ matrículas. Em 2014, a redução foi de 7,07\% (sendo 8,9\% do EF e 3,37\% do EM) em comparação a 2013, que tinha 177.117 matrículas e já computava uma redução de $9,86 \%{ }^{3}$ em comparação com os dados de 2012, quando foram registradas 196.496 matrículas.

Em 2013, a Secretaria de Estado de Educação, em parceria com a Fundação Centro de Ciências e Educação Superior à Distância do Estado do Rio de Janeiro (CECIERJ), implantou, em todas as escolas que ofertam EJA no ensino médio, o Programa Nova Educação de Jovens e Adultos (Nova EJA). Segundo o Relatório da SEEDUC (2014), com esta nova proposta houve um crescimento de escolas ofertando a EJA, passando de 574, em 2012, para 634, em 2013.

O aumento do número efetivo de escolas ofertando EJA no estado, por outro lado, não correspondeu diretamente a um crescimento do número de alunos matriculados nessa modalidade de ensino. Em 2011, a rede possuía $210.789^{4}$ matrículas e, em 2013, reduziu 33,95\%, caindo para 139.234 alunos; destes, 69.738 $(50,1 \%)$ estavam na modalidade semipresencial ${ }^{5}$ (Rio de Janeiro, 2012 e 2014).

2. A redução de matrículas no ensino fundamental no estado foi de $6,67 \%$. O aumento de matrículas no ensino médio de $4,08 \%$ amorteceu a redução geral.

3. A redução de matrículas no ensino fundamental no estado foi de 15,05\%. O aumento de matrículas no ensino médio de $2,7 \%$ amorteceu a redução geral.

4. Os dados não fazem distinção entre matrículas presencial e semipresencial. Neste ano, a Secretaria ainda contabilizava o número de matrículas do Projeto Autonomia separado do regular, com 15.209 alunos.

5. A SEEDUC reconhece as matrículas dessa modalidade como EJA integral. Segundo ela, esta "[...] categorização explica-se pelo fato de que a escola/professores está disponível em período integral aos alunos matriculados nesta modalidade" (Rio de Janeiro, 2014, p. 24). 
Pela análise dos marcos legais e operacionais da EJA nas últimas décadas, é possível evidenciar avanços e retrocessos na política implementada. Em um enorme descompasso entre os marcos, podemos afirmar que conquistamos importantes normativas que regulamentam a execuçáo da política. Porém, por outro lado, essas conquistas não foram efetivadas na prática. Em síntese, os avanços legais náo corresponderam efetivamente em conquistas na consolidação da política de EJA. Além da redução de matrículas, discute-se a qualidade do ensino ofertado no país.

\section{Aspectos políticos, econômicos e sociais da regiáo Costa Verde do estado do Rio de Janeiro}

Diversas são as questóes que envolvem a definição da região Costa Verde no estado do Rio de Janeiro. Para efeitos de divulgação turística, por exemplo, a regiáo compreende todo o território litorâneo que banha os municípios de Mangaratiba, Angra dos Reis, Itaguaí e Parati (no estado do Rio de Janeiro) e Ubatuba, Caraguatatuba, São Sebastião e Ilhabela (no estado de São Paulo).

Visando à organização, ao planejamento e à execução de funçóes públicas e serviços de interesse comum, por meio da Lei estadual n. 1.227/87, que aprovou o Plano de Desenvolvimento Econômico e Social 1988/1991, o estado do Rio de Janeiro está dividido em oito regiōes de governo: Metropolitana, Noroeste Fluminense, Norte Fluminense, Baixadas Litorânea e Serrana, Centro-Sul Fluminense, Médio Paraíba e Costa Verde.

Desde então, foram feitas algumas alterações tanto na denominaçãa quanto na composição dessas regiôes. Conforme a lei complementar n. 105, de 4 de julho de 2002, art. 12, por exemplo, "[...] fica instituída a regiáo da Costa Verde, composta dos Municípios de Itaguaí, Mangaratiba, Angra dos Reis e Parati, com vistas à organização, ao planejamento e à execução de funções públicas e serviços de interesse comum". 
Em 2009, pela lei complementar n. 130, de 21 de outubro de 2009, art. 12, a regiáo Costa Verde passa a ser composta apenas pelos municípios de Mangaratiba, Angra dos Reis e Parati. O município de Itaguaí, conforme o art. 1. ${ }^{\circ}$, passou a integrar a Região Metropolitana do estado.

Para efeito dessa pesquisa, consideramos como parte da regiáo Costa Verde os municípios de Itaguaí, Mangaratiba, Angra dos Reis, Parati e Rio Claro, todos cortados pela Rodovia Rio-Santos.

É importante salientar que, ao longo da sua história, principalmente com a implantação da indústria de construção naval e a abertura da Rodovia Rio-Santos, toda essa regiáo vem sofrendo grandes modificaçôes, não só ambientais como sociais e econômicas.

Por meio dos dados disponíveis no Censo de 2010 do Instituto Brasileiro de Geografia e Estatística (IBGE), foi possível realizar um diagnóstico da populaçáo da regiáo Costa Verde do estado do Rio de Janeiro, principalmente levando em conta os dados relativos à idade, sexo, cor, renda, religiáo, nacionalidade, naturalidade e educação.

Conforme dados da população total dos municípios, a regiáo Costa Verde possui uma população de 370.016 habitantes distribuídos em um território de 3.212,684 km² . Com densidade demográfica de 153,9, a população de Angra dos Reis corresponde a 45,81\% desse total, seguido por Itaguaí com 24,48\%; Parati com 10,14\%; Mangaratiba com 9,85\%; e Rio Claro com 4,7\%.

Com um Produto Interno Bruto (PIB) de R $\$ 153.502 .002,50$, a renda per capita da região é $\mathrm{R} \$ 505,56$. Angra dos Reis tem o maior PIB da região, $\mathrm{R} \$ 60.119 .000,62$, enquanto Rio Claro, o menor, com R $\$ 11.408 .000,51$. A maior renda per capita é de Mangaratiba, com R $\$ 709,95$, e a menor é de Angra dos Reis com R $\$ 354,66$.

Quanto à população residente, 92,17\% está em situação urbana de domicílio. Os municípios com maior número de residências 
em situação rural são Parati, com 26\%, seguido de Rio Claro, com 21\% e Mangaratiba, com 12\%. Já os municípios com os menores índices são Angra dos Reis com 4\% e Itaguaí com 5\%.

Com relação à distribuição da população por faixa etária, $30.986(8,37 \%)$ estão na faixa de zero a cinco anos; 58.593 $(15,83 \%)$ entre seis e quatorze anos; 126.395 (34,15\%) entre quinze e 29 anos; 150.590 (40,69\%) entre trinta e 59 anos; e $34.731(9,38 \%)$ acima de sessenta anos.

Como se evidencia, a maior parte da população na região está na faixa etária economicamente ativa (quinze a 59 anos) - 74,84\%.

Com relação à cor ou raça, 47,22\% da população da regiáo é branca; $42,86 \%$ é parda; $8,58 \%$ preta; $1,07 \%$ amarela; e $0,25 \%$ indígena.

Com relação a pessoas em condiçóes de atividades a partir de quinze anos de idade, 180.627 (51,42\%) se declararam economicamente ativas e 134.593 (38,32\%) não economicamente ativas.

Quanto à distribuição da população da regiâo por religião, $143.501(38,78 \%)$ das pessoas se declararam católicas, 132.662 (35,85\%) evangélicas e 6.772 (1,83\%) espíritas.

Quanto à população residente por nacionalidade na região, $368.666(99,63 \%)$ são brasileiros natos. Destes, 62,62\% são naturais dos seus respectivos municípios e 17,59\% naturais de outras unidades da federação.

Quanto à escolarização da população, 30,44\% frequentavam creche ou escola em 2010 e 8,66\% nunca frequentou creche ou escola. Parati e Rio Claro são os municípios com o maior número de pessoas que nunca frequentaram creche ou escola, 12\% e 11\% respectivamente.

Levando em conta que o público da modalidade de ensino educação de jovens e adultos se refere a pessoas a partir de quinze anos de idade, a região ainda tem uma população, nesta faixa etária, de 15.908 analfabetos e 14.255 pessoas que nunca frequentaram creche ou escola. 


\section{A educaçáo de jovens e adultos na regiáo Costa Verde}

Nos questionários aplicados em 2011 e 2012, foram solicitadas informações aos coordenadores de educação de jovens e adultos dos cinco municípios pesquisados sobre os marcos normativos da EJA; sobre a quantidade de unidades escolares existentes no município; assim como o número de professores e seus perfis; sobre financiamento e recursos para a EJA; sobre espaço físico, gestão administrativa e pedagógica; organização pedagógica e curricular; projeto político pedagógico; material didático; e sobre o perfil das turmas e número de alunos (matriculados, concluintes, evadidos etc.).

Os dados apresentados referem-se às respostas dos municípios pesquisados tanto ao questionário como às entrevistas realizadas ao longo do processo.

A experiência de EJA na regiáo é bastante diversa. Com exceção de Angra dos Reis e Parati que iniciaram suas experiências a partir de 1990, Itaguaí iniciou-as em 1997 e Mangaratiba em 2010. Infelizmente, Rio Claro náo respondeu a questáo.

A experiência de Angra dos Reis se inicia em 1990 como "Regular Noturno"; somente a partir de 2007 é que passou a seguir a proposta como modalidade de ensino prevista na Lei de Diretrizes e Bases da Educação (Lei n. 9.394/96). Por algum tempo, paralelamente ao "Regular Noturno", o município desenvolveu a alfabetização de adultos pelo Movimento de Alfabetização de Jovens e Adultos (MOVA) e de outras parcerias.

Já Mangaratiba, antes de 2010, funcionava como Ensino Fundamental Noturno Acelerado.

Dois dos municípios da regiáo Costa Verde pesquisados foram condecorados com a medalha Paulo Freire: ${ }^{6}$ Mangaratiba, em

6. Prêmio concedido desde 2005 pelo Ministério da Educação, Secretaria de Educação Conti- 
2010, com seu projeto "Relendo o mundo pelas lentes da educação" (da Escola Municipal do Batatal, na Zona Rural); e Angra dos Reis, em 2011, com seu projeto de "Educação de Jovens e Adultos para a tribo indígena Guarani”.

Parati e Itaguaí têm experiências com alfabetização e elevação de escolaridade no primeiro e segundo segmentos do ensino fundamental. Rio Claro, somente com o primeiro segmento do ensino fundamental. Já Mangaratiba, além dessas experiências, seguindo a proposta do antigo Centro de Ensino Supletivo da Secretaria de Estado de Educação (hoje Centro de Educação de Jovens e Adultos, CEJA), também possui turmas de ensino médio semipresencial.

Angra dos Reis, além da alfabetização e de turmas de primeiro e segundo segmentos do ensino fundamental, já teve experiência com o Programa Nacional de Inclusão de Jovens (PROJOVEM) e com um curso de informática e qualificação profissional oferecidos pela Secretaria de Educação por intermédio da Gerência de Ciência e Tecnologia, além de projetos como EJA Guarani e Educação para os jovens e adultos ribeirinhos.

A proposta pedagógica de alfabetização promovida por Parati, Itaguaí e Mangaratiba se desenvolve em um ano, e a de Angra dos Reis, em dois anos.

A proposta pedagógica para as séries iniciais do ensino fundamental, com exceção de Rio Claro, que é de dois anos e meio, é promovida por todos os demais em dois anos. Para as séries finais, todos os municípios desenvolvem suas propostas em dois anos.

O município de Angra dos Reis dispóe de duas unidades escolares que atuam com a EJA no período anual, com duração de oito anos para o ensino fundamental. Mangaratiba possui uma 
experiência com a EJA semipresencial tanto para o ensino fundamental como para o ensino médio, cujo tempo para integralização depende de cada aluno, visto que os estudos se dão por meio de módulos/disciplinas.

Quanto à organização pedagógica, o horário de funcionamento da EJA, em todas as experiências na regiáo, está concentrado no noturno, de 18 a 22 horas. A exceção é Rio Claro, que tem uma classe de educação especial no horário da tarde.

Com exceção de Angra dos Reis e Itaguaí (que não responderam a pergunta), os demais municípios informaram que as unidades escolares não possuem autonomia administrativa e financeira.

Com relação ao número de escolas que ofereciam turmas de EJA em 2011, Angra dos Reis indicava ter quatorze escolas; Mangaratiba, seis; Parati, uma; e Rio Claro, quatro. Somente Itaguaí não respondeu essa questão.

Em relação ao quadro de professores, a rede municipal de Angra dos Reis apontava 1.143, todos do quadro efetivo. Mangaratiba, 943, sendo 670 efetivos (71,04\%) e 273 contratados (28,95\%). Parati, 418 professores, sendo 300 efetivos $(71,77 \%)$ e 118 contratados (28,22\%). Rio Claro, 253 professores, sendo 203 efetivos $(80,23 \%)$ e 50 contratados (19,76\%). Itaguaí não informou.

Atuando na educação de jovens e adultos, Angra dos Reis registrava 197 professores; Itaguaí, 105; Mangaratiba, 86; Parati, 33; e Rio Claro, oito professores.

Quanto ao perfil dos 428 professores de EJA que atuavam na Regiáo, 382 eram efetivos e 46 contratados. A maioria dos contratados na EJA estava em Itaguaí - 29 professores.

Com relação à formação, 156 eram professores com formação apenas de ensino médio; 356 com ensino superior; 65 com curso de especialização; doze com mestrado e três com doutorado.

Infelizmente, esses dados vão se modificando a cada ano. Por isso, é difícil precisar o cenário atual. 
Todos os municípios informaram não existir um plano de cargos e salários específico para professores que atuam na EJA, mas sim para todos os professores que atuam na Rede.

Angra dos Reis informou que, enquanto coordenaçáo de EJA, “[...] na medida do possível, procura manter a matrícula do professor de EJA, evitando complementaçáo de carga horária nessa modalidade".

Assim como ocorre em todo o Brasil, na região Costa Verde foi possível perceber um decréscimo frequente no número de matrículas nos últimos cinco anos. Registrou uma queda de 39,14\%, saindo de 6.683, em 2010, para 4.067, em 2015.

Em uma análise geral da organização dos sistemas municipais de ensino da regiáo pesquisada, foi possível evidenciar a ausência de Projetos Políticos Institucionais das Secretarias Municipais de Educação. Por isso, se justificam a ausência de dados consolidados sobre a demanda para a política implementada, assim como dos sujeitos atendidos; de planejamento em médio e longo prazos; de acompanhamento, monitoramento e avaliação das açóes, gerando projetos de governo de caráter pontual, fragmentado e descontínuo.

\section{Consideraçóes finais}

Durante muitos anos, quando se falava em educação para jovens e adultos, imaginava-se estar tratando de um grupo social homogêneo, com características biopsicossociais bem distintas e definidas. Não se levavam em consideração suas particularidades, especificidades, táo pouco sua diversidade: faixa etária; sexo/ gênero; raça; credo religioso; ocupação profissional; orientação sexual; situação social (privados ou náo de liberdade) etc.

Com os avanços instituídos na área, nos últimos anos, principalmente no âmbito do reconhecimento do direito humano 
fundamental em que se constitui a educação, em seu papel na sociedade contemporânea, a necessidade de compreensão dessas particularidades, para se levar em consideração propostas político-pedagógicas, traz como primordial a compreensão sobre quem são os sujeitos da EJA.

A proposta política que privilegiava a constituição de Agenda Territorial de Desenvolvimento Integrado de Alfabetização e de Educação de Jovens e Adultos representou um importante marco nesta direçáo, visto que vislumbrava possibilitar melhor compreensão dos dados hoje dispersos em estados, regióes, municípios, bairros e comunidades.

Analisando as experiências de políticas públicas implementadas para a educação de jovens e adultos na região Costa Verde do estado do Rio de Janeiro, foi possível evidenciar que os seus problemas não diferem das demais experiências brasileiras. Problemas que vão desde a compreensão do papel da educação para jovens e adultos até a proposta político-pedagógica que não leva em consideração a realidade dos sujeitos, no território.

Neste sentido, defendemos que, além da necessidade de compreensão das características sociais, econômicas, políticas e culturais do território, é fundamental que se leve em consideração o perfil de cada sujeito que demanda a política. Náo podemos, simplesmente, defender a garantia de direito à educaçáo, mas também primar pela qualidade social dessa educação, para que esteja fundamentada nos princípios constitucionais que visam ao "[...] pleno desenvolvimento da pessoa, seu preparo para o exercício da cidadania e sua qualificação para o trabalho" (art. 205 da Constituição Federal).

A EJA não pode continuar sendo feita de ações pontuais, meros projetos de governo, mas sim ser reconhecida como política estratégica para o desenvolvimento humano, social e político regional. 
Compreendendo que a diversidade deve ser entendida como uma construção histórica, cultural, social e econômica das diferenças, analisando os documentos finais da Conferência Nacional da Educação Básica (CONEB, 2008) e da Conferência Nacional de Educação (CONAE, 2010 e 2014), emergem reflexôes importantes que nos ajudam a pensar sobre as atuais discussões na área de EJA. Os documentos chamam a atenção para o consenso na educaçáo brasileira acerca da necessidade da inclusão dos sujeitos de direito, sobretudo quando se observa o caráter excludente da sociedade e suas repercussóes na garantia dos direitos sociais e humanos. Porém, para compreender, agir e garantir a diversidade, são necessários posicionamentos, práticas políticas e o entendimento da relação entre inclusão, exclusão e diversidade, articulados a uma visão ampla de educação e desenvolvimento sustentável. É preciso que a política de inclusão contemple diferenças para além do aspecto social, entendendo-a como noçáo mais ampla e politizada, que tem como eixo o direito ao trato democrático e público da diversidade, em contextos marcados pela desigualdade e pela exclusão social. Também é necessário que as políticas educacionais se estruturem de forma a contribuir na discussão da relação entre formação, diversidade, inclusão e qualidade social da educação básica.

Alguns problemas visíveis no território da regiáo Costa Verde não são diferentes dos que vêm acontecendo em todo o Brasil, principalmente destacando a ausência de um currículo, de uma proposta pedagógica, previsão de recursos e de formação inicial e continuada de docentes e de equipe técnica responsável pela política de EJA — adequados à realidade local.

Por não existir um Projeto Político Institucional nas Secretarias de Educação, fica muito difícil compreender particularidades regionais e construir um sistema de ensino fundamentado na realidade. 
Com o distanciamento da proposta político-pedagógica dos sujeitos, automaticamente reduzem-se matrículas na modalidade, o que, consequentemente, diminui o número de turmas e de escolas que oferecem a EJA. Assim, não é difícil identificar os motivos que hoje justificam o desmantelamento da política de EJA no Brasil.

Estamos vivendo um dos momentos mais críticos da história da nossa democracia. $\mathrm{O}$ golpe parlamentar e empresarial que aprovou o injustificado impeachment em agosto de 2016, orquestrado por uma parte conservadora da sociedade (e apoiado por instituiçóes que se afirmam republicanas), pôs em risco conquistas históricas das classes populares e trabalhadora que continuam ameaçadas depois do resultado das eleiçóes, tanto presidencial quanto no estado do Rio de Janeiro, a considerar os discursos dos eleitos e as poucas propostas visíveis para garantir o direito à educação para todos.

Os últimos acontecimentos no país - destacando-se o resultado das últimas eleiçôes municipais, principalmente em várias capitais do Brasil, como Sáo Paulo e Rio de Janeiro, e a ameaça da aprovaçáo no Congresso de projetos de lei que violam a Constituição de 1988 e escancaram a nossa economia para o capital externo - abrem cicatrizes que tornam a nossa cidadania cada vez mais vulnerável.

Diante da histórica crise política, econômica, institucional e ética que vivemos no Brasil, temo pelo nosso futuro e por todas as conquistas políticas, econômicas e sociais das classes populares na última década. Lamento que estejamos assumindo a cultura da ideologia da direita que acredita e defende a ideia de direitos do EU e direitos dos OUTROS em detrimento de direitos de TODOS.

Com o avanço e consolidação da cultura conservadora no mundo, os últimos acontecimentos têm representado um duro 
golpe nas forças progressistas e democráticas, fortalecendo cada vez mais o discurso conservador apolítico, machista, homofóbico, sexista etc. que não reconhece o "[...] direito de ser igual quando a diferença nos inferioriza e o direito de ser diferente quando a igualdade nos descaracteriza" (Santos, 2003, p. 56).

Sem sombra de dúvida, o campo progressista tem agora (mais do que nunca) o desafio de mobilizar movimentos sociais, centrais sindicais e população em geral em torno de uma possível "frente progressista", em luta por um horizonte menos nebuloso para as futuras geraçóes.

Náo podemos simplesmente aguardar que o tempo dê conta de curar as cicatrizes. Precisamos nos reorganizar e nos reconstruir a partir dos nossos próprios escombros. Precisamos seguir unidos defendendo "nenhum direito a menos" para todos, principalmente recuperando horizontes políticos iniciados em 2003, como a proposta da Agenda Territorial de Desenvolvimento Integrado de Alfabetização e de Educação de Jovens e Adultos.

\section{Referências}

BALL, Stephen e MAINARDES, Jefferson (orgs.). Politicas educacionais: questôes e dilemas. São Paulo: Cortez, 2011.

BRASIL. Agenda Territorial de Desenvolvimento Integrado de Alfabetização e de Educação de Jovens e Adultos. Brasília, Distrito Federal: Ministério da Educação/SECAD, 2008.

IBGE. Síntese dos Indicadores Sociais: uma análise das condiçôes de vida da população brasileira 2012. Rio de Janeiro: IBGE, 2012.

. Censo 2010. Brasília, Distrito Federal: Instituto Brasileiro de Geografia e Estatística (IBGE), 2010.

INEP. Censo Escolar 2015, 2014 e 2013. Brasília, DF: Instituto Nacional de Estudos e Pesquisas Educacionais Anísio Teixeira, 2016, 2015 e 2014. JULIÂO, Elionaldo Fernandes. "A diversidade dos sujeitos da educação de jovens e adultos". In MEDEIROS, Cecília C. et al. Educação de jovens, 
adultos e idosos: saberes, sujeitos e práticas. Niterói: UFF/Cead, 2015, pp. $157-70$.

MACHADO, Maria Margarida. "A educação de jovens e adultos no Brasil pós-Lei 9.394/96: a possibilidade de constituir-se como política pública". In ___org.). Educação de Jovens e Adultos. Em Aberto, v. 22, n. 82, pp.17-39, Brasília, nov. 2009.

MARINHO, Leila Mattos Haddad de Monteiro. Entre nós e encruzilhadas: as trajetórias dos jovens de 15 a 17 anos na EJA em Angra dos Reis (dissertaçáa). Niterói, 2015.

ORTIZ, Renato. Universalismo e diversidade. São Paulo: Boitempo, 2015.

RIO DE JANEIRO. Secretaria de Estado de Educação (SEEDUC). SEEDUC em números: transparência na educação. Rio de Janeiro, SEEDUC: 2012, 2013 e 2014.

SANTOS, Boaventura de Sousa. Reconhecer para libertar: os caminhos do cosmopolitanismo multicultural. Rio de Janeiro: Civilização Brasileira, 2003.

SENNETT, Richard. A corrosäo do caráter: as consequências pessoais do trabalho no novo capitalismo. Rio de Janeiro: Record, 1999.

SEN, Amartya. Desenvolvimento como liberdade. São Paulo: Companhia das Letras, 2010.

SOUZA, Marcelo José Lopes de. "O território: sobre o espaço e o poder, autonomia e desenvolvimento". In CASTRO, Iná Elias de et al. Geografia: conceitos e temas. Rio de Janeiro: Bertrand Brasil, 1995. 